\title{
Correction to: Evaluation of a machine learning classifier for metamodels
}

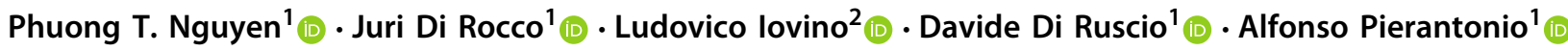

Published online: 9 November 2021

(c) The Author(s) 2021

\section{Correction to: \\ Software and Systems Modeling https://doi.org/10.1007/s10270-021-00913-x}

Unfortunately, in the original publication, reference 70 was published wrongly as "Rössler, A. M. S., Günnemann, S.: Thingml+: Augmenting model-driven software engineering for the internet of things with machine learning. In: R. Hebig and T. Berger, editors, Proceedings of Workshops co-located with MODELS 2018, Copenhagen, Denmark, October, 14, 2018, volume 2245 of CEUR Workshop Proceedings, pp 521-523. CEUR-WS.org, (2018)."

The original article can be found online at https://doi.org/10.1007/ s10270-021-00913-x.

$凶$ Davide Di Ruscio

davide.diruscio@univaq.it

Phuong T. Nguyen

phuong.nguyen@univaq.it

Juri Di Rocco

juri.dirocco@univaq.it

Ludovico Iovino

ludovico.iovino@gssi.it

Alfonso Pierantonio

alfonso.pierantonio@univaq.it

1 Università Degli Studi Dell'Aquila, L'Aquila, Italy

2 Gran Sasso Science Institute, L'Aquila, Italy
The correct reference should be "Moin, A., Rössler, S., Günnemann, S.: Thingml+: Augmenting model-driven software engineering for the internet of things with machine learning. In: R. Hebig and T. Berger, editors, Proceedings of Workshops co-located with MODELS 2018, Copenhagen, Denmark, October, 14, 2018, volume 2245 of CEUR Workshop Proceedings, pp 521-523. CEUR-WS.org, (2018).

We regret the inconvenience caused.

The original article has been corrected.

Open Access This article is licensed under a Creative Commons Attribution 4.0 International License, which permits use, sharing, adaptation, distribution and reproduction in any medium or format, as long as you give appropriate credit to the original author(s) and the source, provide a link to the Creative Commons licence, and indicate if changes were made. The images or other third party material in this article are included in the article's Creative Commons licence, unless indicated otherwise in a credit line to the material. If material is not included in the article's Creative Commons licence and your intended use is not permitted by statutory regulation or exceeds the permitted use, you will need to obtain permission directly from the copyright holder. To view a copy of this licence, visit http://creativecomm ons.org/licenses/by/4.0/.

Publisher's Note Springer Nature remains neutral with regard to jurisdictional claims in published maps and institutional affiliations. 